\title{
Chapter 5 \\ Protocol for Screening for Salt Tolerance in Barley and Wheat
}

\begin{abstract}
A simple protocol is presented that tests salt tolerance in wheat and barley seedlings. The method is based on a glasshouse, aerated hydroponics test in which salt is added to the nutrient hydroponic solution in which the seedlings are grown. A list of equipment is provided including hydroponic hardware and stock solutions. Advice is given on seed storage prior to use and pregermination treatments that promote even germination of test samples. Salt treatments commence after seedling establishment in hydroponics at the 2-3-leaf stage. Visual symptoms of salinity stress include reduced leaf area, whitish appearance of lower leaves, leaf tip death, leaf rolling and seedling death. Recommended test salt concentrations for testing wheat and barley are given along with a method of recovering selected plants. Examples of protocol used are also given.
\end{abstract}

\subsection{Introduction}

The protocol for rice needs to be adapted for other cereals such as wheat and barley. Changes are required for germination, aeration of hydroponics and test concentration. Wheat and barley seeds do not germinate well when submerged and therefore cannot be germinated in the hydroponics platforms. Seeds are therefore pregerminated and young seedlings are transferred to hydroponics. Also, wheat and barley cannot tolerate anaerobic growing conditions, and their roots need to be aerated in hydroponics. Moreover, wheat and barley are more tolerant to salt than rice and therefore are tested at higher concentrations.

\subsection{Adaptations of Rice Protocol to Wheat and Barley}

\subsubsection{Germination}

Germination of wheat and barley may be improved by pretreatment with $0.8 \%$ sodium hypochlorite; this serves to surface sterilise the seed and promotes more 
synchronous germination. Solutions of sodium hypochlorite can be easily made from commercial bleach (about $5 \% \mathrm{NaClO}$ ). The pretreatment involves soaking seed in $0.8 \% \mathrm{NaClO}$ for $20 \mathrm{~min}$ and then washing three times with water. Seed (up to 50) may be placed onto wetted filter paper in Petri dishes (4 $\mathrm{ml}$ water per $9 \mathrm{~cm}$ Petri dish, water should not cover the seed). The Petri dishes are then placed in the dark at $4{ }^{\circ} \mathrm{C}$ (fridge) for $48 \mathrm{~h}$; this low temperature facilitates uniform germination. Seeds are best germinated in sandwich blots, which produce vertical root systems (Fig. 5.1). The pretreated seeds are placed into sandwich blots which are held in a rack placed in a dish of water at room temperature $\left(17-25^{\circ} \mathrm{C}\right)$ in lit conditions. After 5-6 days, seedlings of uniform development are removed and placed into hydroponics. Alternatively, pretreated seed in Petri dishes may be transferred to room temperatures $\left(17-25{ }^{\circ} \mathrm{C}\right)$ in the light for another $48 \mathrm{~h}$, replenishing water when necessary (when the Petri dish is tilted, there should be an excess of about $1 \mathrm{ml}$ water). After 4 days in the light, germinated seeds should have the first leaf emerging from the coleoptile and 3-8 roots (Fig. 5.1b). These seedlings are removed individually and placed inside a sponge collar and inserted into the hydroponic system (Fig. 5.2a, b).

\subsubsection{Hydroponic Solution}

The hydroponic system is the same as that described for rice except full-strength Yoshida solution is used from the beginning of hydroponics. Hoagland's solution may also be used as an alternative (this is commonly used in research of wheat and barley) (Hoagland and Arnon 1950) (Table 5.1).
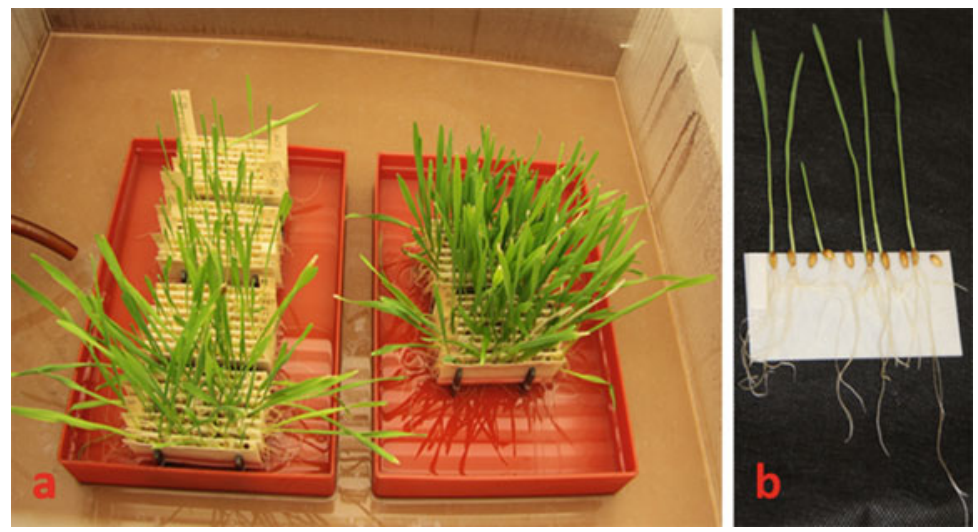

Fig. 5.1 (a) Sandwich blots for germinating wheat and barley seed to obtain vertical root systems. (b) Opened sandwich blot with barley (or wheat) seedlings; those of uniform growth are transferred to the hydroponic system 

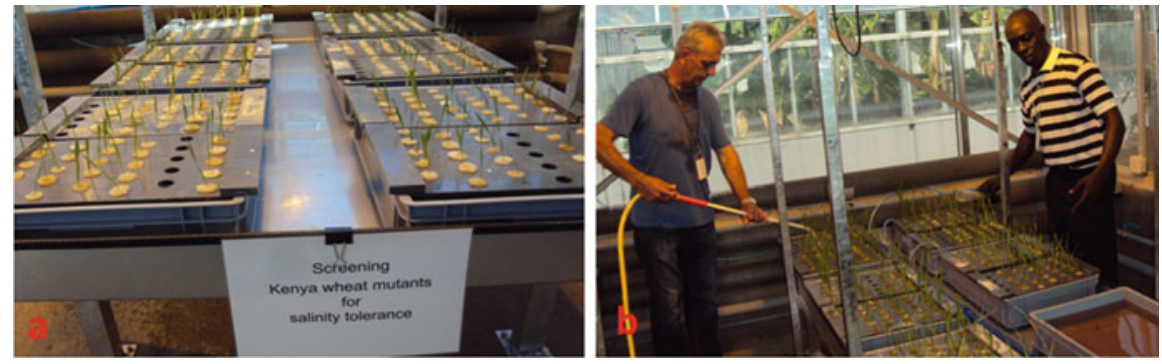

Fig. 5.2 (a) Wheat seedlings set into the hydroponic system in the glasshouse. (b) Wheat seedlings at the 2-3-leaf stage ready for salt screening treatment

Table 5.1 Composition of Hoagland's solution

\begin{tabular}{l|l}
\hline Chemicals & $\mathrm{mg} \mathrm{l}^{-1}$ \\
\hline $\mathrm{NH}_{4} \mathrm{H}_{2} \mathrm{PO}_{4}$ & 115 \\
\hline $\mathrm{H}_{3} \mathrm{BO}_{3}$ & 2.86 \\
\hline $\mathrm{Ca}\left[\mathrm{NO}_{3}\right]_{2} \cdot 4 \mathrm{H}_{2} \mathrm{O}$ & 945 \\
\hline $\mathrm{MgSO}_{4} \cdot 7 \mathrm{H}_{2} \mathrm{O}$ & 250 \\
\hline $\mathrm{MnCl}_{2} \cdot 4 \mathrm{H}_{2} \mathrm{O}$ & 1.81 \\
\hline $\mathrm{KNO}_{3}$ & 607 \\
\hline $\mathrm{FeSO}_{4} \cdot 7 \mathrm{H}_{2} \mathrm{O}$ & 5.0 \\
\hline
\end{tabular}

Seedlings are grown on to the two-leaf stage and should appear green and healthy prior to testing.

\subsubsection{Aeration}

Wheat and barley and other cereals cannot be grown in hydroponics without aeration (rice can be grown without aeration because it has specialised aerenchymatous root cells). Aeration is supplied by pumping air into the hydroponics through plastic tubes feeding metal aeration rods. The tubes are attached to a central ring tube, and a ring system provides uniform pressure; feeder tubes are fitted to the central ring. The ends of the feeder tubes are fitted with $20-30 \mathrm{~cm}$ long steel tubes that are perforated with small holes (about $1 \mathrm{~mm}$ in diameter) to allow small air bubbles to escape (Fig. 5.3). Metal aeration tubes are used as they sink to the bottom of the tanks and do not interfere with root growth.

Some convenient sizes which we recommend are:

- Ring tube: internal diameter $25 \mathrm{~mm}$

- Feeder tube: internal diameter $0.6 \mathrm{~mm}$

- Aeration rod: internal diameter $0.6 \mathrm{~mm}$ 

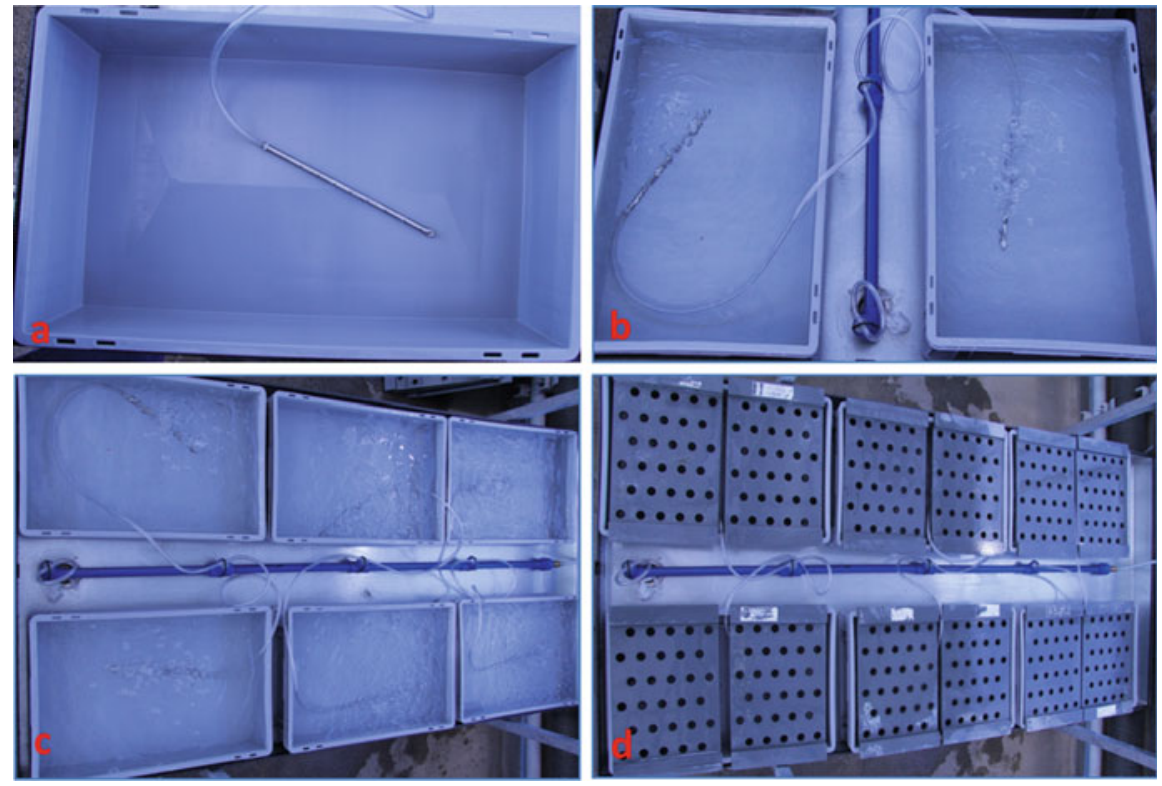

Fig. 5.3 Aeration system used for wheat and barley. (a) Steel tube perforated with small holes (aeration rod); the steel tube should be of sufficient weight to lie horizontally at the bottom of the hydroponic tank and not interfere with the root system of the seedlings. (b) Feeder tube with steel tube end piece for aeration placed into hydroponic tank and showing the gentle air bubbling. (c) Aeration system showing gentle air bubbling in the tanks. (d) Aeration system and support platforms ready for growing wheat and barley in hydroponics

\subsubsection{Glasshouse Conditions}

The test is normally carried out in a glasshouse set-up for temperate crops: $20 / 15^{\circ} \mathrm{C}$ (day/night) with a $16 \mathrm{~h}$ photoperiod.

Aeration rods can be made from $0.6 \mathrm{~mm}$ steel tubing cut to length with one end sealed by clamping.

With this system, 6-10 hydroponic tanks can be accommodated on a bench of $2 \times 1 \mathrm{~m}$ (Fig. 5.3c, d).

As soon as seedlings go into hydroponics, they are aerated.

\subsubsection{Test Salt Concentrations}

Plants differ greatly in their tolerance of salinity. Wheat and barley are more tolerant to salinity than rice. Therefore, different salt concentrations are used. Typical concentrations used for screening wheat and barley are $15-20 \mathrm{dS} \mathrm{m}^{-1}$ or 150-200 mmol NaCl, compared to $10 \mathrm{dS} \mathrm{m}^{-1}$ or $100 \mathrm{mmol} \mathrm{NaCl}$ for rice. 
Salt treatments are applied to seedlings established in hydroponics (two-leaf stage in Hoagland's solution). This is done by transferring the platform of seedlings from control tanks to hydroponic tanks containing the test $\mathrm{NaCl}$ concentration in Yoshida solution. This is a one-step method. An alternative is to add salt in daily increments of $25 \mathrm{mmol}$ until the test concentration is reached (this will reduce the effect of osmotic shock).

\section{Reference}

Hoagland DR, Arnon DI (1950) The water culture method for growing plants without soil. College Agriculture circular No. 347, College of Agriculture, University of California, Berkeley 